\title{
The Integration Program of Prevention and Treatments of Substance Use and HIV/AIDS in the Rural Primary Health Care (PHC) System of
}

\section{Iran}

\author{
Mohammad Bagher Saberi Zafarghandi, ${ }_{1}$ Yalda Tabasi, ${ }^{2,}$ Jafar Bolhari, ${ }^{3}$ Ali Baghbanian, ${ }^{3}$ Somayeh \\ Yazdani, ${ }^{4}$ Mohammad Ali Adibfar, ${ }^{4}$ Mohsen Jadidi, ${ }^{5,}{ }^{*}$ and Mahboubeh Dadfar ${ }^{6}$ \\ ${ }^{1}$ Department of Addiction, School of Behavioral Sciences and Mental Health, Tehran Institute of Psychiatry, Mental Health Research Center, Iran University of Medical \\ Sciences, Tehran, IR Iran \\ ${ }^{2}$ School of Behavioral Sciences and Mental Health (Tehran Institute of Psychiatry), Iran University of Medical Sciences, Tehran, IR Iran \\ ${ }^{3}$ Department of Community Psychiatry, School of Behavioral Sciences and Mental Health (Tehran Institute of Psychiatry), Iran University of Medical Sciences, Tehran, IR Iran \\ ${ }^{4}$ Ministry of Health and Medical Education, Bureau of Mental Health and Substance abuse \\ ${ }^{5}$ Department of Psychology, Islamic, Azad University, Bandargaz Branch, Bandargaz, IR Iran \\ ${ }^{6}$ Department of Clinical Psychology, School of Behavioral Sciences and Mental Health, Tehran Institute of Psychiatry, International Campus, Iran University of Medical \\ Sciences, Tehran, IR Iran \\ "Corresponding authors: Yalda Tabasi, School of Behavioral Sciences and Mental Health (Tehran Institute of Psychiatry), Iran University of Medical Sciences, Tehran, IR Iran, \\ E-mail: ytabasi@gmail.com; Mohsen Jadidi, Department of Psychology, Islamic, Azad University, Bandargaz Branch, Bandargaz, IR Iran. Tel: +98-9123000074, Fax: \\ +98-2166506853, E-mail: Jadidi.mohsen@gmail.com
}

Received 2015 April 10; Revised 2016 January 19; Accepted 2016 January 30.

\begin{abstract}
Background: Drug abuse is the most problematic issue in many countries including Iran. Prevention, treatment and demand reduction programs of drug abuse have the highest priorities. In 2004, Iran's ministry of health and medical education (MOME) integrated prevention and treatment substance use and human immunodeficiency virus infection/acquired immune deficiency syndrome (HIV/AIDS) programs in the rural primary health care (PHC) system.

Objectives: The aim of the present study was to evaluate the integration program of prevention and treatment of substance use and HIV/AIDS in the rural primary health care (PHC) system of Iran.

Patients and Methods: This was a cross sectional descriptive/qualitative study about supervision, assessment and monitoring by mental health experts team during year 2009. Data was collected mostly from an expert panel, which monitored the program accurately.

Results: The findings showed that the program was used in 380 health houses in 10 cities of Iran. The total number of inhabitants covered by the program were 5555258 , and 8245 of them were substance abusers. The cases were registered and their data were reported by the managers. The function of health houses, health centers, and district health centers were assessed by considering the number of cases. The centers provided care services, interventions and harm reduction activities, and they referred some cases to specialists or other higher-level professional centers. Many educated experts including Behvarzes, multipurpose health workers, primary health personnel, educated general physicians (GPs) and family physicians (GFs) had worked actively in rural health centers. Furthermore, at district level, executive groups followed up cases were referred by (GFs).

Conclusions: Integrating program of prevention and treatment of substance use and HIV/AIDS in PHC system of Iran has positive outcomes. It is one of the most effective ways in this domain. It has a coherent structure, and a high potential in the introducing of PHC services to the community. The program has important impacts on the provision of health services and representation of mental health in rural areas. It seems that the program successes in the most of its goals, and can be continued and enhanced with some changes and reforms in the country.
\end{abstract}

Keywords: Integration, Primary Health Care, Substance Abuse, Iran

\section{Background}

Misuse of illicit drugs, prescription drugs or alcohol is a world-wide problem (1), which affects people of different ages and socioeconomic status (2-5); there is a national and international commitment to provide effective prevention and treatment services in different dimensions such as change in attitudes, health education and social learning
(6). Some studies indicated that exercise-based treatments and civil commitment were effective for substance use (7, $8)$. The issue could be compromising. Drugs and drugusing behavior are associated with delinquency $(9,10)$, antisocial behaviors and suicide risk (11). It seems that drug abuse neutralizes shame and guilt experiences after committing violent behaviors (12). Consumption, possession, 
manufacturing and distributing drugs are classified as illegal behavior in most countries so that they have provided multifaceted strategies to control the use of drugs and related concerns $(13,14)$.

The Islamic Republic of Iran, with a population estimated at 80 million in 2015, which ranks 17th in the world (http://worldpopulationreview.com/countries/iranpopulation), is a country in Western Asia. It is bordered to the east with Afghanistan, a source country for opiates worldwide (Southeast Asia Opium Survey 2014 Lao PDR, Myanmar UNODC Regional Office for Southeast Asia and the Pacific) and Pakistan (http://www.nationsonline.org/oneworld/iran.htm). Iran is affiliated with the world health organization (WHO) sponsored Alma-Ata declaration of 1978, aimed at health for all in the Year 2000 (report of the international conference on primary health care Alma-Ata, USSR, 6-12 September 1978 WHO- GENEVA 1978).

The integration of mental health in primary health care system started in two pilot projects in two cities of Shahreza and Shahri Kurd in 1987. The project established continuously and had a growing trend in all parts of the country. Some enhancing movements in this way include establishment of a mental health department in Iran's ministry of health, introduction of mental health as the ninth division in the PHC system, holding a national mental health committee, preparing educational packages at all levels of primary health services, increasing awareness of public and health personnel through a monitoring process, assigning a week for mental health, holding workshops/seminars and conferences. In 2004, Iran's ministry of health subsumed substance abuse treatment and HIV prevention in the rural PHC system. The health status of Iranians has improved over the last three decades. Iran has been able to extend public health preventive services through the establishment of an extensive primary health care network in rural and urban areas (https://en.wikipedia.org/wiki/Health care_in_Iran). In the Iranian health network, the executive unit at district level is health houses, rural and urban health centers, rural health workers, Behvarzes, and education center for Behvarz, district health centers and district general hospitals. All of them operate through supervision of the district health network.

Opium and its derivations have a long history in Iran's tradition so that pharmacological and psychotropic effects are found in people with difficulties. The current situation is increasing gradually in Iran (15), and may have different side effects worldwide (16). Many researchers believe that due to lack of policies for drug control and prevention, the drug can serve as a way for suicide attempt (17). Drugs, especially injecting type, have a major role in distribution of infectious disease such as HIV/AIDS (18). In 1970s, the estimation of opium addicts in Iran was 600000 people ( $2 \%$ of the general population) (19). A rapid situation assessment, carried out by national studies in 2007, estimated 1200000 drug abusers in Iran (2.2\% of the adult population). From 250000 opiate abusers, $20 \%$ were injecting drugs. According to reports of Addiction and mental health office of the ministry of health of Iran (2007), from 3277 cases, $64 \%$ of HIV positive cases were infected from substance injection. Due to comorbidity of HIV/AIDS with drug consumption, injective drug abuse is a considerable health issue, because it is correlated with social problems such as violence, crime and high risk driving (20). There is drug abuse in prisons of Iran. The majority of prisoners are charged with drugrelated to crimes. Prison systems and correctional centers are facing problems such as overcrowding, violence and high risk behaviors, for example injecting drug use, unsafe tattooing, unprotected sex and sexual transmitted infections (21), and hepatitis C (22).

In respect to the program of integrating substance use prevention to PHC systems, the 8th version of the research guideline includes four level strategies for integration of the same strategies in the PHC. The main emphasis of the program is prevention of incidence and prevalence of substance abuse and harm reduction through providing general and particular education at all levels of the PHC system. A study was done in 2010, and a pilot study of integration was implemented in 10 districts in several provinces a few years ago. However, some case reports indicated inefficiency and gaps in delivery services, and thus, the evaluation of the program was implemented in 2009. Although drug abuse has negative effects, there is still a gap in prevention programs in the country. Iran's ministry of health integrated substance abuse and HIV prevention program in the rural PHC system. Today, addiction is a worldwide crisis and needs to motivate all resources, especially PHC policymakers.

\section{Objectives}

The aims of the present health system research (HSR) was to evaluate the effectiveness of integrating substance prevention pilot programs in $\mathrm{PHC}$, to determine barriers of the program, and try to provide recommendations for promotion of the program in the health care system of Iran.

\section{Patients and Methods}

This was a cross sectional descriptive/qualitative and a rapid assessment study relying on the HSR regarding supervision, assessment and monitoring by mental 
health experts team of universities in 2009. Data was collected based on a precise schedule, mostly from an expert panel, which monitored the program accurately. Statistical data was obtained from centers for addiction control, and observing program progress, evidences, and documents in several field visit, meetings and discussions with executive teams and observing evidence-based progress across different levels of the health system in 10 cities of four provinces between June to December 2009. The study investigated the current process, delivery systems, staff/clients satisfaction in the field of services, outcomes of services, and qualification of program implementation based on the indicators of the 8th version of the manual of integration substance abuse prevention in the PHC of Iran. Ten universities established independent teams, which consisted of six experts, who were educated, 60 experts for extracting of information and about 50250 clients. They dealt with the execution of the program. Substance abuse prevention and treatment office (SAPTO) prepared individual and group deep interviews and focused group discussions; and then they educated other experts of the universities. Focus groups consisted of 20 scholars and key experts, who evaluated the activities, operations and executive issues of the program in four sessions. A semi-structured checklist provided by SAPTO of the health ministry of Iran, was used. It consisted of two sections (the first section was designed to assess awareness and attitudes of Behvarzes, clients, GPs and technicians; and the second section was designed to assess performance of Behvarzes, GPs, technicians and mental health experts).

\section{Results}

The findings showed that the program has been implemented in 380 health houses and ten cities of Iran. Inhabitants who were covered by the program included $5,555,258$ individuals, and 8245 of them were substance abusers. The cases registered and their data were reported by the managers. The function of health houses and centers, and district health centers were assessed by a number of clients. The centers provided care services, interventions, and harm reduction activities and they referred some cases to specialists or other more professional centers. Many educated experts including Behvarzes, multipurpose health workers, primary health personnel, educated general physicians (GPs) and Family Physicians (FPs) had been working actively in rural health centers. Furthermore, at district level, an executive group followed up cases that were referred by GPs. Qualitative results of the present study are shown in Table 1.

\section{Discussion}

Drug abuse and mental health inseparably are at the top ranking of disorders in the world and also in Iran (23). Although advances have been obtained nationally and regionally in the zone of primary mental health care and prevention of drug abuse, there are serious challenges, which threat accession of the programs in Iran; it seems that there would be probable menaces in the future if more accurate studies and evaluations, especially in the integration of the two programs is not performed by the ministry of health (24).

Reports and evaluations of the two recent decades in Iran have indicated that primary health care had been influential and succeeded in delivering health services particularly once integrating with mental health affairs (2527). Studies need to consider potential and practical strategies if they intend to be productive; staff training, educating the community, concerning preventive measures and reducing harm for substance drug users are among of necessary factors (23-28). Results of the present study are consistent with other studies (19), and support the notion that it will be significantly effective if professionals integrate preventive and intervention programs in PHC and health services.

The program encountered some challenges in Iran; and the PHC requires a more holistic, community-based and comprehensive approach in order to obtain clear and firm outcomes. One of the challenges related to policymaking and law issues is removal, such difficulties that may result in more precise preventive outputs (24-29).

A similar report conducted in Kaski district, Western Nepal showed that patient care provided by the studied health facilities, was insufficient and thus an effective intervention program for promotion of rational drug use practice in PHC facilities, was recommended (30). Regardless of pros and cons, the program is a vigorous tool in addiction control and treatment. Intervention and harm reduction strategies were hardly applied based on all dimensions of instructions. There were several conflicts in tasks of different district/universities and organizations. For instance, although based on the program, intervention was a responsibility of the medical department, health departments also implemented treatments for addicts. These interdisciplinary conflicts could decline productivity of the programs.

The PHC system is coherently structured and highly capable of providing health services both in urban and rural regions. Traditionally, such programs are intended for prevention, early detection and early intervention of health problems. The six priorities that should be provided by services are diagnosis and treatment, emergency services, 
Table 1. Qualitative Results

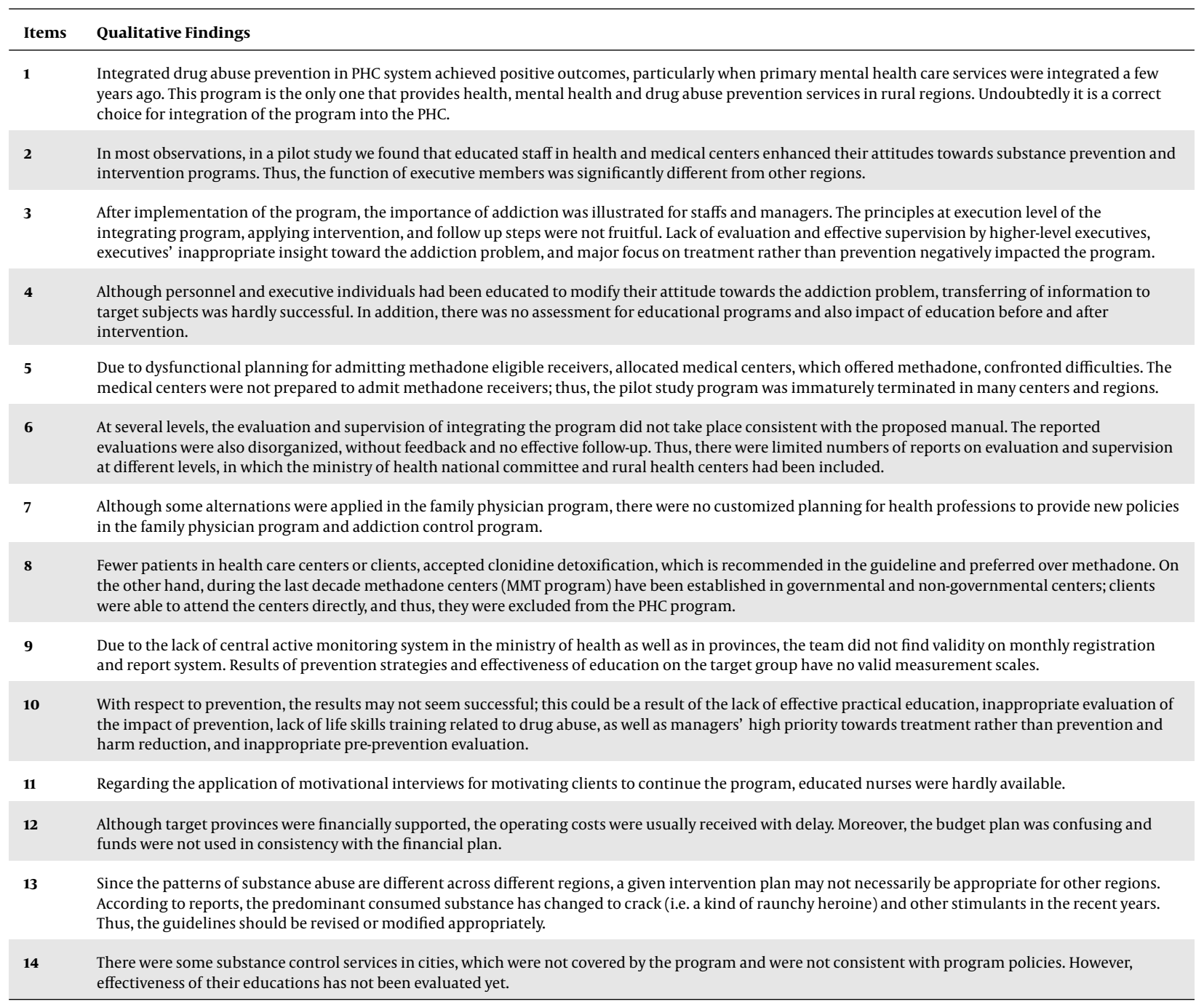

family planning, preventive health services, including immunizations and health education; engaging these programs starts with community strengths, the community's assessment of health issues, and aims for community con$\operatorname{trol}(31)$.

Therefore, it seems that rural health houses and primary health centers are preferred sites for integrating the program with health and medical services. As mentioned previously, there are still deficiencies in the program that needs further modifications including:

Modifications and upgrading protocols and instructions through an immediate agenda as well as planning for more effective strategies in prevention, intervention, demand and harm reduction; in order to design an effective program and implement it efficiently. It is critical for organizations and departments to be cooperative in all areas and dimensions. Both non-governmental and public clinics, which provide methadone, should admit referred clients and deliver intervention and follow-up programs. Continuous progress and constant improvement by executive experts, policy makers and universities, through permanent supervision, monitoring and evaluation is necessary to achieve benefits of system potentials. Supervising strategies and functions with a valid national and local evaluation in the entire field of study and effective financial management are essential to achieve the program goals. For recording data and document activities, it is preferred to use electronic data recording. Employ all aspects of primary health systems capacities practically and effectively to elaborate community mental health in risky 
group members, as well as in prevention level including educating life skills and parenting skills congruent with mental health programs, and due to several gaps in literature of substance-related studies in prevention programs and primary healthcare services, further studies are recommended.

One of the main purposes of delivering PHC services is demand reduction, which can ultimately decrease rate of demands for drug consumption in the community. According to a report of mental, social health and addiction office of the ministry of health and medical education (MOME), Saberi Zafarghandi et al. (2007) indicated that PHC activities could encompass and cover different populations, which deal with drug issues; also qualitative and quantitative extension of such programs might result in an increase of clients' satisfaction and motivation of PHC employees.

Estimations of United Nations Office on Drugs and Crime (UNDOC) (2012) indicated that between 162 to 324 million people, and between $3.5 \%$ and $7.0 \%$ of the world population aged between 15 and 64, have used an illicit drug, mainly a substance such as cannabis, opium, cocaine or amphetamine-type stimulants, at least once in the previous year. The prevalence of opiate dependency in Afghanistan, Iran and Pakistan is the highest globally (average of $1.5 \%$ of the adult population in the three countries), whereas it is $0.8 \%$ in Central Asia (twice the global average). With reference to the period from 21st of March 2011 to 19th of March 2012, experts found an increase in both opium and heroin use in Iran.

Studies showed that PHC is an effective program, which enhances trust, collegial communication and interdisciplinary collaboration (32). The most important achievement of the project of integration of mental health into the PHC is reduction of load of hospital professional services. This integration is successful in this area and can continue with some changes and reforms $(33,34)$.

Overall, the findings showed that integrating program of prevention and treatment of substance use and HIV/AIDS in PHC system of Iran has positive outcomes. It is one of the most effective ways in this domain. It has a coherent structure, and a high potential in introducing PHC services to the community. The program has important impacts on the provision of health services and representation of mental health in rural areas. It seems that the program successes in most of its goals, and can continue and advance with some changes and reforms in the country.

\section{Acknowledgments}

We appreciate the experts and advisors, especially Drs. Jandaghi, Eshrati, Jafari, Momtazi, Nikfarjam, Gilanipur,
Sadeghi, Zeinal Zadeh, Khaleghi, Saverolia, Fathi, Mrs.//Ms. Karimi Keysami, Asadi, Davasaz Irani, Ghorbani Shokohizadeh, Asl Rahimi, Bahramnejad, Kaviani, Haghighat, Ahmad Pourian, Morad Haghighian, Hojatollah, Heidari, Baftehchi, and Eskandri, for their compassionate and considerable feedbacks and suggestions. We warmly thank the office of addiction and psychosocial health in ministry of health, substance abuse prevention and intervention department for providing easy access to significant research, projects and studies.

\section{Footnote}

Authors' Contribution: Mohammad Bagher Saberi Zafarghandi, Yalda Tabasi, Jafar Bolhari, and Ali Baghbanian guided and executed the study; Somayeh Yazdani, Mohammad Ali Adibfar prepared the data and article; Mohsen Jadidi edited the article.

\section{References}

1. Drazdowski TK, Jaggi L, Borre A, Kliewer WL. Use of prescription drugs and future delinquency among adolescent offenders. J Subst Abuse Treat. 2015;48(1):28-36. doi: 10.1016/j.jsat.2014.07.008. [PubMed: 25135798].

2. Abbasi-Ghahramanloo A, Fotouhi A, Zeraati H, Rahimi-Movaghar A. Prescription drugs, alcohol, and illicit substance use and their correlations among medical sciences students in iran. Int J High Risk Behav Addict. 2015;4(1):21945. doi: 10.5812/ijhrba.21945. [PubMed: 25821750].

3. Gunderson EW. Recognizing potential buprenorphine medication misuse: product packaging does not degrade with laundering. Subst Abus. 2015;36(2):161-5.

4. Ashrafioun L, Bohnert ASB, Jannausch M, Ilgen MA. Evaluation of the current opioid misuse measure among substance use disorder treatment patients. J Subst Abuse Treat. 2015;55:15-20.

5. Oreskovich MR, Shanafelt T, Dyrbye LN, Tan L, Sotile W, Satele D, et al. The prevalence of substance use disorders in American physicians. Am JAddict. 2015;24(1):30-8. doi:10.1111/ajad.12173. [PubMed: 25823633].

6. Espada JP, Gonzalvez MT, Orgiles M, Lloret D, Guillen-Riquelme A. Meta-analysis of the effectiveness of school substance abuse prevention programs in Spain. Psicothema. 2015;27(1):5-12. doi: 10.7334/psicothema2014.106. [PubMed: 25633763].

7. Linke SE, Ussher M. Exercise-based treatments for substance use disorders: evidence, theory, and practicality. Am J Drug Alcohol Abuse. 2015;41(1):7-15. doi: 10.3109/00952990.2014.976708. [PubMed: 25397661].

8. Cavaiola AA, Dolan D. Considerations in civil commitment of individuals with substance use disorders. Subst Abus. 2016;37(1):181-7.

9. Nakawaki B, Crano W. Patterns of substance use, delinquency, and risk factors among adolescent inhalant users. Subst Use Misuse. 2015;50(1):114-22. doi: 10.3109/10826084.2014.961611. [PubMed: 25290663].

10. Maniglio R, Innamorati M. Psychosocial correlates of adolescent cannabis use: data from the Italian subsample of the second International Self-Reported Delinquency study.JAddict Dis. 2014;33(3):210-20. doi: 10.1080/10550887.2014.950023. [PubMed: 25115199].

11. Narvaez JC, Jansen K, Pinheiro RT, Kapczinski F, Silva RA, Pechansky F, et al. Psychiatric and substance-use comorbidities associated with lifetime crack cocaine use in young adults in the 
general population. Compr Psychiatry. 2014;55(6):1369-76. doi: 10.1016/j.comppsych.2014.04.021. [PubMed: 24933652].

12. Havnes I, Clausen T, Brux C, Middelthon A. The role of substance use and morality in violent crime-a qualitative study among imprisoned individuals in opioid maintenance treatment. Harm reduct J. 2014;11(1):1.

13. Reuter P. Can tobacco control endgame analysis learn anything from the US experience with illegal drugs?. Tob Control. 2013;22 Suppl 1:4951. doi: 10.1136/tobaccocontrol-2012-050809. [PubMed: 23591511].

14. Mbwambo J, McCurdy SA, Myers B, Lambdin B, Kilonzo GP, Kaduri P. Drug trafficking, use, and HIV risk: the need for comprehensive interventions. SAHARA J. 2012;9(3):154-9. doi: 10.1080/17290376.2012.743832. [PubMed: 23237070].

15. Raisdana F, Nakhjavani A. The drug market in Iran. 2002.

16. Ahmadi B, Arab P, Zahedi MJ, Shafieipour S, Drossman DA, Banivaheb G. Prevalence of narcotic bowel syndrome in opioid abusers in iran. Middle East J Dig Dis. 2014;6(4):208-13. [PubMed: 25349684]

17. Hassanian-Moghaddam H, Zamani N, Rahimi M, Shadnia S, Pajoumand A, Sarjami S. Acute adult and adolescent poisoning in Tehran, Iran; the epidemiologic trend between 2006 and 2011. Arch Iran Med. 2014;17(8):534-8. [PubMed: 25065275].

18. Spiller MW, Broz D, Wejnert C, Nerlander L, Paz-Bailey G, Centers for Disease C, et al. HIV infection and HIV-associated behaviors among persons who inject drugs-20 cities, United States, 2012. MMWR Morb Mortal Wkly Rep. 2015;64(10):270-5. [PubMed: 25789742]

19. Mclaughlin GT. The poppy is not an ordinary flower: Survey of drug abuse in iran. Fordham Law Rev. 1976;44:728-34.

20. Schultz NR, Blonigen D, Finlay A, Timko C. Criminal typology of veterans entering substance abuse treatment. J Substance Abuse Treat. 2015;54:56-62.

21. Javanbakht M, Boudov M, Anderson LJ, Malek M, Smith LV, Chien M, et al. Sexually transmitted infections among incarcerated women: findings from a decade of screening in a Los Angeles County Jail, 2002-2012. Am J public health. 2014;104(11):103-9.

22. Alvarez KJ, Befus M, Herzig CT, Larson E. Prevalence and correlates of hepatitis $C$ virus infection among inmates at two New York State correctional facilities. J Infect Public Health. 2014;7(6):517-21. doi: 10.1016/j.jiph.2014.07.018. [PubMed: 25182508].

23. Whiteford HA, Degenhardt L, Rehm J, Baxter AJ, Ferrari AJ, Erskine HE, et al. Global burden of disease attributable to mental and substance use disorders: findings from the Global Burden of Disease Study 2010 2013 ; 13:611-6.

24. Saberi Zafarghandi MB. Some challenges on Iranian mental health and addiction prevention programs. Iran J Psychi Clin Psycho. 2011;17(2):157-61.

25. Mohit A, Shamohammadi D, Bolhari J. National evaluation of Iranian mental health program. Iran J Psychi Clin Psycho. 1998;3.

26. Bolhari J, Ahmadkhaniha HR, Hajebi BA, Bagheri Yazdi SA, Naserbakht M, Karimi-Kisomi I, et al. Evaluation of mental health program integration into the primary health care system of iran. Iran J Psychi Clin Psycho. 2012;17(4):271-8.

27. Shariat SV, Mansouri N, Gharraee B, Bolhari J, Nourai RY, Rahimi M. Attitude, knowledge, and satisfaction of health personnel and general population about the program of integration of mental health in phc in iran: A systematic review. Iran J Psychi Clin Psycho. 2011;17(2):85-98.

28. Eskandarieh S, Jafari F, Yazdani S, Hazrati N, Saberi-Zafarghandi MB. Compulsory maintenance treatment program amongst Iranian injection drug users and its side effects. Int J High Risk Behav Addict. 2014;3(4):21765. doi: 10.5812/ijhrba.21765. [PubMed: 25741482].

29. Saberizafarghandi MB, Roshanpazhuh M, Mirkazemi R, Bolhari J. Fundamental challenges of contraction of demand reduction program in primary health care in iran: Report of an expert panel.J Iran Psychi and Clin Psychol. 2014;19(4):326-9.

30. Dahal P, Bhattarai B, Adhikari D, Shrestha R, Baral SR, Shrestha N. Drug use pattern in primary health care facilities of kaski district, western Nepal. Sunsari Tech College J. 2013;1(1):1-8.

31. Baum F. Health for All Now! Reviving the spirit of Alma Ata in the twenty-first century: An Introduction to the Alma Ata Declaration. Social Med. 2007;2(1):34-41.

32. Kotecha J, Brown J, Han H, Harris S, Green M, Russell G, et al. Influence of a quality improvement learning collaborative program on team functioning in primary healthcare. Families, Systems, Health. 2015;33(3):222

33. Dadfar M, Bolhari J, Dadfar F. Integration of prevention of child sexual abuse in Primary Health Care (PHC) in Iran. Iran J Psychi, Suppl 2012;7(40):22-3.

34. Dadfar M, Bahrami. F. . Descriptive Reports of Integration of Mental Health into the Primary Health Care (PHC) System in One of the Areas of Iran. Am J Edu Res. 2015;3(11):1429-32. 